\title{
Effect of hydration therapy on oligohydramnios
}

\author{
Cicily T. J.*, Sherin Sams, Anitha K. Gopal
}

Department of Obstetrics and Gynecology, Government Medical College, Kottayam, Kerala, India

Received: 20 March 2017

Accepted: 01 April 2017

*Correspondence:

Dr. Cicily T. J.,

E-mail: dr.cicilytj@gmail.com

Copyright: () the author(s), publisher and licensee Medip Academy. This is an open-access article distributed under the terms of the Creative Commons Attribution Non-Commercial License, which permits unrestricted non-commercial use, distribution, and reproduction in any medium, provided the original work is properly cited.

\section{ABSTRACT}

Background: Oligamnios is defined as an AFI $<5 \mathrm{~cm}$, SDP $<2 \mathrm{cms}$ or an AFI below the 5 th centile for the gestational age and is associated with many maternal and perinatal complications. An effective, non-invasive method of increasing AFV is the hydration therapy. The objective of present study was to determine the impact of hydration therapy in patients complicated by oligamnios and to measure the maternal and perinatal outcome in oligamnios corrected by Intravenous hydration therapy.

Methods: It is a randomised control trial done at Government Medical College, Kottayam, Kerala, India from Jan 2012 to May 2013. 136 singleton pregnant females with gestation age $>34$ weeks with AFI $<5$ cms were randomised into an Intervention group who receive 1 litre of ringer lactate i.v given daily for 5 days and nonintervention group who were kept under observation by serial ultrasound and antepartum fetal surveillance. All were followed-up till delivery to obtain maternal and perinatal outcomes.

Results: Among the 68 who were given intervention, 61 responded and 7 were non responders. With hydration therapy, mean increase in AFI was $4 \mathrm{~cm}$ and minimum duration needed for improvement was one week. Hydration therapy showed significant improvement in the maternal and fetal outcomes. Intravenous route of maternal hydration has the advantage that a fixed amount of fluid can be infused at a relatively constant rate with ensured compliance.

Conclusions: From the study, it was concluded that Hydration therapy is an excellent method to improve AFI in Oligohydramnios and maternal and perinatal outcome.

Keywords: Amniotic Fluid, Amniotic Fluid Index, Fetal growth retardation, Hydration therapy, Oligohydramnios

\section{INTRODUCTION}

Amniotic Fluid (AF) is an important part of pregnancy sac and helps fetal development. ${ }^{1}$ Amniotic fluid has a number of important functions like development of musculoskeletal system, gastrointestinal tract development, lung development, provides essential nutrients to fetus, protects fetus from trauma, and maintains body temperature and it has bacteriostatic properties. $^{2}$

Amniotic Fluid Volume (AFV) rises to a plateau between 22-39 weeks of gestation reaching up to $700-850 \mathrm{mls}$, which corresponds to an Amniotic Fluid Index (AFI) of
14-15 cm. ${ }^{3,4}$ Evaluation of amniotic fluid by palpation is deceptive, whereas its assessment on ultrasonography (USG) is more reliable. ${ }^{5}$ Oligohydramnios occurs in about $1 \%$ to $5 \%$ of pregnancies at term. ${ }^{6}$

AFI is assessed by ultrasound, using which an AFI of 5.0 $\mathrm{cm}$ or less is defined as oligohydramnios. ${ }^{7}$ It was added to ante partum testing, to better identify fetuses at higher risk of poor perinatal outcome. ${ }^{8}$

By the second and third trimester, amniotic fluid is produced primarily by fetal urine and is reabsorbed through fetal swallowing, fetal lung and directly by the placenta. ${ }^{9}$ Amniotic fluid volume is affected by the status 
of maternal hydration and maternal plasma osmolality. Acute oligohydramnios may occur from ruptured membranes. ${ }^{10,11}$ Chronic oligohydramnios arises from chronic fluid leakage, pre renal, renal, and post renal causes in the fetus. ${ }^{12}$

Irrespective of the cause, oligohydramnios may be responsible for problems such as malpresentation, umbilical cord compression, concentration of meconium stained liquor, difficult or failed external cephalic version, difficult ultrasound visualisation of fetal parts, pulmonary hypoplasia, fetal heart rate deceleration, increased chance of caesarean section (CS), nonreactive non-stress tests, intrauterine growth restriction (IUGR), congenital abnormalities, postdate pregnancy, and low Apgar scores. ${ }^{13-16}$

Sequelae of chronic oligohydramnios can be fetal demise, pulmonary hypoplasia, facial and skeletal deformities. ${ }^{17}$ Because adverse outcomes occur in highrisk pregnancies complicated by low amniotic fluid volume, oligohydramnios commonly prompts labour induction, which increases the incidence of caesarean delivery, particularly for the primiparous woman with an unripe cervix. ${ }^{18}$

Among a number of interventions that have been tried to improve the AFV; bed rest, high protein diet, alanine infusion, 1-deamino-[8-D-arginine] vasopressin, transabdominal and transvaginal amnioinfusion, vesicoamniotic shunt, $10 \%$ maltose infusion and oral and intravenous hydration therapy. ${ }^{19-24}$ But one that's cost effective, simple to accomplish, with less side effects, which do not require special techniques and successful outcome, is the hydration therapy.

Maternal hydration therapy has been suggested by many authors to restore amniotic fluid volume to its normal range and thereby to reduce the associated perinatal morbidity and mortality. ${ }^{25,26}$ Maternal hydration may theoretically increase amniotic fluid volume by causing fetal diuresis and by improving placental perfusion. An effective, non-invasive method of increasing amniotic fluid volume may have several applications in obstetric practice.

Intravenous hypotonic solution significantly increases the hourly fetal urine production. ${ }^{27}$ Studies have shown that human fetus can monitor the acute changes in osmolality by increasing the urine production to maintain its fluid homeostasis. ${ }^{28}$ Also, hydration increases amniotic fluid in oligamnios but not in patients with normal AFI, and hydration is associated with increase in mean uterine artery velocity. ${ }^{29}$

Intravenous route of maternal hydration is advantageous over oral to increase amniotic fluid volume as intravenous route seems to have the advantage that a fixed amount of fluid can be infused at a relatively constant rate with ensured compliance. ${ }^{30}$ Early detection of oligohydramnios and its correction by simple maternal hydration is found to improve perinatal outcome. The objectives of present study were:

- To determine the impact of hydration therapy in patients complicated by oligohydramnios.

- To measure the maternal and perinatal outcome in oligohydramnios corrected by intravenous hydration therapy compared to non-intervention group.

\section{METHODS}

It is a randomised control trial done at Government medical college, Kottayam, Kerala, India from Jan 2012 to May 2013, after the approval from ethical committee. Proper informed consent was obtained from all the patients after explaining the benefits of the study.

\section{Inclusion criteria}

- Singleton pregnancy

- Well established gestational age

- All medical disorders related to present pregnancy

- Non anomalous fetus

- Intact membranes at the time of selection

\section{Exclusion criteria}

- Congenital anomalies

- Intrauterine death

- Multiple pregnancies

- Past date

- $\quad$ PROM and PPROM

- Medical diseases unrelated to pregnancy

136 singleton pregnant females with gestation age $>34$ weeks with AFI $<5 \mathrm{cms}$ were taken up for trial. All patients were submitted for elaborate clinical examination and obstetric examination along with detailed history taking to satisfy the inclusion and exclusion criteria. AFI was assessed sonographically. After obtaining a written informed consent, patients were randomly selected in two groups.

- Intervention group - those who receive hydration therapy (1 litre of Ringer Lactate i.v given daily for 5 days and the response reassessed with ultrasonogram after the treatment).

- Non-intervention group - those who were kept under close maternal and fetal monitoring by serial ultrasound and antepartum fetal survivals.

All of them were followed up till delivery to obtain maternal and perinatal outcomes.

\section{Statistical analysis}

Data was initially entered into an excel file and was entered SPSS software data variable. The categorical 
variables were analysed by chi square test. Univariable analysis was done and a $\mathrm{p}$ value less than 0.05 was taken as statistically significant.

\section{RESULTS}

Table 1: Improvement of AFI in both groups.

\begin{tabular}{|llll|}
\hline Improvement & $\begin{array}{l}\text { Intervention } \\
\text { Group }\end{array}$ & $\begin{array}{l}\text { Non } \\
\text { intervention } \\
\text { group }\end{array}$ & Total \\
\hline Yes & 61 & 6 & 67 \\
\hline No & 7 & 62 & 69 \\
\hline Total & 68 & 68 & 136 \\
\hline
\end{tabular}

Among the 136 females taken up for study, 68 were given hydration therapy and the rest 68 were kept under observation without intervention. 61 among the intervention group showed improvement in AFI whereas among the non-intervention group only 6 had an improvement.

Table 2: Change in the AFI in both groups.

\begin{tabular}{|lll|}
\hline Difference in AFI & $\begin{array}{l}\text { Intervention } \\
\text { group }\end{array}$ & $\begin{array}{l}\text { Non-intervention } \\
\text { group }\end{array}$ \\
\hline Mean & 4.0081 & 0.4897 \\
\hline Standard deviation & 2.52462 & 0.88235 \\
\hline t value & 13.869 & \\
\hline p value & 0.000 & \\
\hline
\end{tabular}

The mean improvement in AFI in the intervention group was 4. From the data collected, analysis was done by paired t test, which showed a t value of 13.869 and a $p$ value of 0.000 , which is statistically significant. Hydration therapy therefore is proven to improve AFI in oligohydramnios.

Table 3: Patient characteristics.

\begin{tabular}{|lllll|} 
& Experimental & Control & test statistic & p \\
Age & $26.5+4.9$ & $27.0+5.0$ & 0.589 & $>0.05$ \\
\hline Gestational age & 35 weeks 2 days+7.9 & 35 weeks 2 days+9.1 & 1.4 & $>0.05$ \\
\hline Primi & $36(52.9 \%)$ & $35(31.5 \%)$ & 0.864 & $>0.05$ \\
\hline
\end{tabular}

Table 4: Maternal outcome.

\begin{tabular}{|lllll|} 
& Experimental & Control & Test statistic & p \\
\hline Improvement in AFI & $61(89.7 \%)$ & $6(8.8 \%)$ & 88.9 & $<0.05$ \\
\hline Mean difference in AFI & $4.0+2.5$ & $0.4+0.8$ & 13.8 & $<0.05$ \\
\hline Spontaneous labour & $45(66.2)$ & $27(39.7)$ & 9.5 & $<0.05$ \\
\hline Induction needed & $23(33.8)$ & $41(60.2)$ & 9.6 & $<0.05$ \\
\hline Vaginal delivery & $48(70.6)$ & $20(29.4)$ & 23.1 & $<0.001$ \\
\hline Instrumental delivery & $2(2.9)$ & $4(5.9)$ & 0.174 & $>0.05$ \\
\hline Emergency caesarian section & $10(14.7)$ & $29(42.6)$ & 12.9 & $<0.001$ \\
\hline Deliveries complicated by MSAF & $1(1.5)$ & $14(20.6)$ & 12.7 & $<0.001$ \\
\hline Abruption & 0 & $3(4.4)$ & & $0.244^{*}$ \\
\hline
\end{tabular}

Table 5: Fetal outcome.

\begin{tabular}{|lllll|}
\hline & Experimental & Control & test statistic & p \\
\hline NRFHR & $6(8.8)$ & $31(45.6)$ & 23.2 & $<0.001$ \\
\hline 1'Apgar $<6$ & $4(5.9)$ & $9(13.2)$ & 2.1 & $>0.05$ \\
\hline IUGR & $28(41.2)$ & $40(58.8)$ & 10.7 & $<0.001$ \\
\hline RDSAB & $3(4.4)$ & $32(47.1)$ & 32.3 & $<0.001$ \\
\hline MAS & $1(1.5)$ & $9(13.2)$ & & $0.017^{*}$ \\
\hline NICU & $6(8.8)$ & $31(45.6)$ & 59.1 & $<0.001$ \\
\hline IUD & $1(1.5)$ & $1(1.5)$ & & $1.000^{*}$ \\
\hline NND & $3(4.4)$ & $3(4.4)$ & & 1.000 \\
\hline
\end{tabular}

Extremes of maternal age were avoided and preference were given equally to the primi gravidas and multi gravidas from a gestational age of 34 to 40 weeks, avoiding past date pregnancies.

\section{DISCUSSION}

At Medical College Kottayam, on an average we have 150 women attending our outpatient clinic daily and 
deliveries in the institutions per month ranges from 450 500. The incidence of oligamnios in our hospital was found to be $2.8 \%$. In India, incidence of oligamnios ranges from $1-5 \%$.

Maternal characteristics of the women taken for the study were evenly distributed among the intervention and nonintervention group and outcomes were studied in detail. The most common etiological factor contributing to oligohydramnios was found to be associated with intrauterine growth restriction (50\%). Medical disorders contributing to oligohydramnios constituted only $19.8 \%$. Isolated oligamnios constituted $30.2 \%$.

During hydration therapy, we found no changes in maternal vital signs and peripheral venous pressure. No patient discontinued the study because of adverse effects.

IV hydration was given by ringer lactate solution and $89.17 \%$ responded to hydration therapy and $10.29 \%$ did not respond. The mean improvement in AFI in the intervention group was $4 \mathrm{~cm}$. Present study findings are consistent with the studies conducted by Dor et al, Magann et al, Hofmeyr and Gulmeziglu, Nicola et al and Chandra et al who concluded that IV hypotonic fluid increases AFI in oligamnios. ${ }^{4,26,31-33}$ Mean number of days required to increase AFI was 7 days.

Among the intervention group, $66.18 \%$ went into spontaneous labour pains ( $\mathrm{p}$ value of 0.0025 ) compared to $39.71 \%$ in the non-intervention group. The rest 33.82 $\%$ in the intervention group were either induced or taken up for elective cesarean section.

Induction of labour (according to the modified Bishop score) was done for $33.82 \%$ of intervention group ( $p$ value is 0.0025$)$ and $60.29 \%$ of non-intervention group. ${ }^{34,35}$ Among the $33.82 \%$ induction was done for past date, on date, associated co morbidities like GDM, Gestational Hypertension and IUGR and Doppler abnormalities. In non-intervention group, all were induced for intrauterine growth restriction, oligamnios and associated Doppler abnormalities.

Among the patients who went into spontaneous labour pains, $70.59 \%$ were among the intervention group ( $p$ value 0.000 ) and $29.41 \%$ were among the nonintervention group. But among the non-intervention group, who had vaginal delivery all were given trans vaginal amnioinfusion during labour, either prophylactically or therapeutically. There was 1 case of assisted breech delivery in the intervention group.

Instrumental delivery was needed in $2.94 \%$ of intervention group ( $\mathrm{p}$ value of 0.50 ) and $5.88 \%$ among the non-intervention group. Of intervention group, one was delivered by ventouse for failure of secondary powers and one by forceps for fetal bradycardia whereas four among non-intervention were delivered by ventouse/forceps for fetal bradycardia.
Elective CS was conducted for $11.77 \%$ of the intervention group ( $p$ value 0.70 ) and $10.29 \%$ of nonintervention group. Among the intervention group, 6 were previous CS and two were flexed breech. 7 were taken up for elective CS in the non-intervention group for flexed breech (6) and previous CSc (1).

Emergency CS was done for $14.7 \%$ of intervention ( $p$ value 0.000 ) and $42.6 \%$ of non-intervention. 10 among intervention group were taken up for emergency CS for previous CS and premature rupture of membrane (4), failed induction (4) and NRFHR (2). 29 among the nonintervention group were taken for emergency CS for meconium stained amniotic fluid (14), abruption placentae (3) and non-reassuring fetal heart rate (12).

Meconium stained amniotic fluid was seen in $1.47 \%$ of the intervention group (Light MSAF); p value 0.000 and $20.59 \%$ of non-intervention group (2-Light MSAF, 7Moderate MSAF and 6-Thick MSAF). 10 cases complicated by MSAF in the non-intervention group developed meconium aspiration syndrome and needed resuscitation and supportive care in NICU, except one (died on day 1), all others were discharged after treatment.

Abruptio placentae complicated $0 \%$ in intervention (p value is 0.20 ) compared to $4.41 \%$ in nonintervention group. All 3 cases were grade II abruption needing emergency CS.

Non-reassuring fetal heart rate was seen in $8.8 \%$ of the intervention ( $p$ value 0.000 ) and $45.6 \%$ of the nonintervention. 6 in the intervention group were taken up for emergency CS whereas 12 in the nonintervention group were taken up for emergency CS, 4 were delivered by instruments and rest 15 cases delivered vaginally. All 15 were given intrapartum amnioinfusion following nonreassuring fetal heart rate.

Perinatal asphyxia (1' Apgar <6) was seen in $5.9 \%$ of intervention group ( $\mathrm{p}$ value 0.10 ) and $13.24 \%$ of nonintervention group. All babies needed neonatal resuscitation. 6 babies died in NICU (3 in each group).

$41.2 \%$ of intervention group had low birth weight babies ( $\mathrm{p}$ value 0.001 ) and $58.8 \%$ of non-intervention group. The IUGR babies in intervention group had a better outcome than the non-intervention group.

Respiratory distress soon after birth was found in $4.4 \%$ of intervention ( $\mathrm{p}$ value 0.000 ) and $47.1 \%$ of nonintervention group needing NICU care.

No cases of Meconium aspiration syndrome were seen in intervention group (p value 0.001 ) compared to $14.7 \%$ in non-intervention group. One baby in the non-intervention died due to meconium aspiration syndrome, two babies were resuscitated and were discharged. 
NICU admissions were needed for $8.8 \%$ among intervention and $45.59 \%$ of non-intervention group ( $p$ value 0.000). 6 in the intervention group (nonresponders) were admitted in NICU for evaluation and treatment and 31 of the non-intervention, needed NICU admission because of the complications of low birth weight, respiratory distress syndrome and meconium aspiration syndrome.

There were 2 still births, one in each group (p value 0.99 ). Still born baby in the intervention group was found to have congenital anomaly and that in the nonintervention group, was a premature (35 weeks 5 days) severely compromised fetus with Doppler abnormality.

There were 3 neonatal deaths in each group ( $p$ value 0.99). One baby had renal agenesis, one was preterm infant of diabetic mother, and breech and third baby was having severe IUGR, oligamnios and Doppler abnormality. In the non - intervention group, one baby had meconium aspiration syndrome, one baby was having extremely LBW and one baby was having severe IUGR, oligamnios and Doppler abnormality.

\section{CONCLUSION}

From the study, it was concluded that hydration therapy is an excellent method to improve AFI in Oligohydramnios and maternal and perinatal outcome. The mean increase in AFI in intervention group was 4 $\mathrm{cm}$. The minimum duration needed to improve AFI was 1 week. Among 68 intervention group, 61 responded to the treatment whereas 7 did not respond, reasons being undetected fetal anomaly, placental insufficiency and oligamnios in irreversible phase. The maternal and perinatal outcomes in the corrected group were also proved to be better than the uncorrected group where the response was poor. By correction of AFI early induction needed for oligohydramnios was avoided. Maternal outcomes in intervention group, with respect to spontaneous labour pain, induction, vaginal delivery, emergency caesarean section and meconium stained liquor, were par excellent compared with nonintervention group, whereas outcomes with respect to instrumental delivery, abruptio placentae and Elective Caesarean delivery were not significant. Perinatal outcomes in intervention group, with respect to non reassuring fetal heart rate, low birth rate, respiratory distress soon after birth, meconium aspiration syndrome, NICU care were excellent compared with nonintervention group, whereas outcomes like 1' Apgar $<6$, neonatal deaths and still births were not statistically significant in both groups.

\section{Recommendations}

The results of this research recommend promoting hydration therapy with intravenous Ringer Lactate at a dose of one litre on daily or alternate day basis for five days, for treating oligohydramnios. Early detection of
Oligohydramnios and its correction by simple maternal hydration is found to improve perinatal outcome by increasing amniotic fluid volume by fetal diuresis and improving placental perfusion. Hydration therapy with intravenous hypotonic solution is a cost effective, easy method of treatment, having fewer side effects and with a successful outcome. Intravenous route of maternal hydration is advantageous over oral to increase Amniotic fluid volume as intravenous route seems to have an advantage that a fixed amount of fluid can be infused at a relatively constant rate with ensured compliance.

\section{ACKNOWLEDGMENTS}

Authors are extremely thankful to Dr. Sherin Sams, Department of OBG, Government Medical College Kottayam, Kerala, India. Authors are also thankful to Dr. Jayageetha and Dr. Babu statisticians for the valuable suggestion and guidance. Authors express their sincere thanks to all patients who participated in this study. Above all, Authors are grateful to God Almighty for his blessings that have led to the completion of present study.

Funding: No funding sources Conflict of interest: None declared

Ethical approval: The study was approved by the Institutional Ethics Committee

\section{REFERENCES}

1. Cunningham FG, Leveno KJ, Bloom SL, Hauth JC, Gilstap LC, Wenstrom KD. Fetal growth and development. In: Cunningham FG, Leveno KL, Bloom SL et al, eds. Williams Obstetrics. 23rd ed. New York, NY: McGraw-Hill; 2010:chap 4.

2. Ross MG, Brace R. Amniotic fluid biology- basic and clinical aspects. J Matern Fetal Med. 2001;10:219.

3. Larmon JE, Ross BS. Clinical utility of amniotic fluid volume assessment. Obstet Gynecol Clin North Am. 1998; 25:639-61.

4. Magann EF, Sanderson M, Martin JN Jr, Chauhan SP. The amniotic fluid index, single deepest pocket, and two-diameter pocket in normal human pregnancy. Am J Obstet Gynecol. 2000;182:1581-8.

5. Magann EF, Nolan TE, Hess LW, Martin RW, Whitworth NS, Morrison JC. Measurement of amniotic fluid volume: Accuracy of ultrasonography techniques. Am J Obstet Gynecol. 1992;167:1533-7.

6. Voxman EG, Tran S, Wing DA. Low amniotic fluid index as a predictor of adverse perinatal outcome. J Perinatol. 2002;22:282-5.

7. Phelan JP, Ahn MO, Smith CV, Rutherford SE, Ander-son E. Amniotic fluid index measurements during preg-nancy. J Reprod Med. 1987;32:601-4.

8. Manning FA, Harman CR, Morrison I, Menticoglou SM, Lange IR, Johnston JM. Fetal assessment based on fetal biophysical profile scoring IV. An analysis of perinatal morbidity and mortality. Am J Obstet Gynecol. 1990;162:703-9. 
9. Lotgering FK, Wallenburg HCS. Mechanisms of production and clearance of amniotic fluid. Semin Perinatol. 1986;10:94.

10. Lisa A, Martin, James N. Effect of maternal hydration on amniotic fluid volume. Jr MD Obstet Gynecol. 2003;101(6):1261-5.

11. Magann EHF, Chauhan SP, Martin JN. Oligohydramnios at term and pregnancy outcome. Fetal Mater Medic Rev. 2001;12(3):209-27.

12. Ott WJ. Reevaluation of the relationship between amniotic fluid vol and perinatal outcome. Am J Obstet Gynecol. 2005;192:1803-09.

13. Golan A, Lin G, Evron S. Oligohydramnios: maternal complications and fetal outcome in 145 cases. Gynecol Obstet Invest. 1994;37:91-5.

14. Grubb DK, Paul RH. Amniotic fluid index and prolonged antepartum fetal heart rate decelerations. Obstet Gynecol. 1992;79:558-60.

15. Manning FA, Hill LM, Platt LD. Qualitative oligohydramnios: clinical association and predictive value for amniotic fluid volume determination by ultrasound: antepartum detection of intrauterine growth retardation. Am J Obstet Gynecol. 1981;139:254-8.

16. Sultana S, Akbar Khan MN, Khanum Akhtar KA, Aslam M. Low amniotic fluid index in high risk pregnancy and poor Apgar score at birth. J Coll Physicians Surg Pak. 2008;18(10):630-4.

17. Casey BM, McIntire DD, Bloom SL, Lucas MJ, Santos R, Twickler DM et al. Pregnancy outcomes after ante partum diagnosis of oligohydramnios at or beyond 34 weeks' of gestation. Am J Obstet Gynecol. 2000;182:909-12.

18. Kawasaki N, Nishimura H, Yoshimura T, Okamura H. A diminished intrapartum amniotic fluid index is a predictive marker of possible adverse neonatal outcome when associated with prolonged labour. Gynecol Obstet Invest. 2002;53:1-5.

19. Gülmezoglu AM1, Hofmeyr GJ. Bed rest in hospital for suspected impaired fetal growth. Cochrane Database Syst Rev. 2000;(2):CD000034.

20. Ahmad JK. Intravenous amino acid therapy in Oligohydramnios; Practitioner. 2006;13(3):140-1.

21. Ross MG, Cedars L, Nijland MJM, Ogundipe A. Treatment of oligohydramnios with maternal 1deamino-[8-D-arginine] vasopressin-induced plasma hypoosmolality. Am J Obstet Gynecol. 1996;174:1608-13.

22. Gramellini D, Fieni S, Kaihura C, Piantelli G, Verrotti C. Antepartum amnioinfusion: a review. J Mater Fetal Neonat Medic. 2003;14:291-6.
23. Suzuki S, Mine K, Sawa R, Yoneyama Y Araki T. $10 \%$ maltose infusion therapy for oligohydramnios. Australian New Zealand J Obstet Gynaecol.1991;39:373-5.

24. Magann EF, Doherty DA, Chauhan SP, Barrilleaux SP, Verity LA, Martin JN Jr. Effect of maternal hydration on amniotic fluid volume. Obstet Gynecol. 2003;101(6):1261-5.

25. Egan JFX. Maternal hydration and its effect on the amniotic fluid index [abstract]. Am J Obstet Gynecol. 1996;174(1 Pt 2):416.

26. Hofmeyr GJ, Gulmezoglu AM. Maternal hydration for increasing amniotic fluid volume in oligohydramnios and normal amniotic fluid volume. Cochrane Database Syst Rev. 2002;(1):CD 000134.

27. Battaglia F, Prystowsky H, Smisson C, Hellegers A, Bruns P. Fetal blood studies. XIII. The effect of the administration of fluids intravenously to mothers upon the concentrations of water and electrolytes in plasma of human fetuses. Pediatr. 1960;25:2-10.

28. Oosterhof H, Hack MC, Aamoudse JG. Acute maternal rehydration increases the urine production rate in the near-term human fetus; Am J Obstet Gynecol. 2000;183(1):226-9.

29. Flack NJ, Sepulveda W, Fisk NM. Acute maternal hydration in third-trimester oligohydramnios: Effects on amniotic fluid volume, uteroplacental perfusion, and fetal blood flow and urine output. Am J Obstet Gynecol. 1995;173:1186-91.

30. White SA, Goldhill DR. Is Hartmann's the solution?. Anaesthesia. 1997;52(5):422-7.

31. Doi S, Osada H, Itoh K, Ikeda K, Sekiya S, Takehisa T. Effect of maternal hydration on oligohydramnios: a comparison of three volume expansion methods [abstract]. Am J Obstet Gynecol. 1998;178:S156.

32. Flack NJ, Sepulveda W, Fisk NM. Acute maternal hydration in third-trimester oligohydramnios: Effects on amniotic fluid volume, uteroplacental perfusion, and fetal blood flow and urine output. Am J Obstet Gynecol. 1995;173:1186-91.

33. Chandra PC, Schiavello HJ, Lewandowski MA. Effect of oral and intravenous hydration on oligohydramnios. J Reprod Med. 2000;45:337-40

34. Bishop EH. Pelvic scoring for elective induction. Obstet Gynecol. 1964;24(2):266-8.

35. Royal College of Obstetricians and Gynaecologists; RCOG clinical effectiveness support unit. induction of labour. Evidence-based Clinical. London: RCOG Guideline. 2001;9.

Cite this article as: Cicily TJ, Sams S, Gopal AK. Effect of hydration therapy on oligohydramnios. Int J Reprod Contracept Obstet Gynecol 2017;6:1800-5. 